\title{
Biographical Encyclopedia of
}

\section{Communication Study: Fostering}

\section{Historiography and Memory in the Field}

\section{Thomas Wiedemann}

Ludwig Maximillian Universität München, thomas.wiedemann@ifkw.lmu.de

\section{Michael Meyen}

Ludwig Maximillian Universität München, michael.meyen@ifkw.lmu.de

This essay Reflects our work and experience as editors of the Biographical Encyclopedia of Communication Study (Biografisches Lexikon der Kommunikationswissenschaft, or BLexKom) ${ }_{1}{ }^{1}$ which presents the main protagonists in the German-speaking communication field from its beginnings until today and simultaneously showcases the literature on the field's history. Considering our project as a work in progress that encourages scholars to contribute, we launched BLexKom in 2013 with a small number of entries (about 20) and some additional interview material. Since then, BLexKom has grown tremendously in size and dimension. We now count more than 140 biographical entries and several dozen in-depth interviews. We also integrated supplementary formats and sections into our platform, including research papers, canonic texts, autobiographical reflections, features (e.g., on journalism education in the German Democratic Republic), and obituaries.

This essay aims to provide a deeper insight into the BLexKom project, whose relevance extends well beyond the German case. To be clear, we do not consider BLexKom as a research output per se, nor do we think of it as the only legitimate history of communication
Thomas Wiedemann and Michael Meyen, "Biographical Encyclopedia of Communication Study: Fostering Historiography and Memory in the Field," History of Media Studies 1 (2021), https://doi.org/ 10.32376/d895aoea.74443024.

\section{(C) (i) (5)}

\footnotetext{
${ }^{1}$ BLexKom is supported by the publisher Herbert von Halem, Cologne, and designed as an open-access platform. It is available online at http://blexkom. halemverlag.de.
} 
as an academic discipline in Germany. Instead, by offering as many sources as possible, we designed our platform in an effort to foster research on the discipline's development, appearance, and orientation, and to stimulate memory processes in the field. To support this claim and make the argument for BLexKom plausible, it is first necessary to describe the theoretical alignment of our project and make its conceptualization comprehensible. Second, it seems equally important to discuss our role as editors, in particular regarding the challenges associated with our decision-making as source providers. Beyond that, we believe that our experience with BLexKom might hold interest for research projects that deal with the history of communication studies in different contexts, especially more contemporary ones. We therefore, third, report in this essay on the reactions and, in particular, on the critical feedback from the community, which has in turn triggered self-reflection processes for us. After all, BLexKom does not leave people indifferent, and perhaps this is something we should consider when reasoning on the difficult situation of specialized historiography in communication studies, ${ }^{2}$ which, to a certain extent, may also apply to the social sciences in general.

\section{Theoretical Alignment of BLexKom}

Although BLexKom includes different formats that allow foci on intellectual and institutional approaches as well, the encyclopedia platform is mainly conceptualized as a biographical window onto the history of communication studies. This does not mean reproducing the myths about the so-called founding fathers of the discipline, which have been criticized as "thin hagiography" 3 and "great-menmake-history-tales"4-the case of Elisabeth Noelle-Neumann, to give just one example, makes clear that the literature on the history of the German field is far from an exception to the rule here. 5 More precisely, BLexKom draws on the sociology of science's assumption that the development of an academic discipline results from cognitive and social parameters. ${ }^{6}$ We additionally assume that this development always reflects the background of its most important figures and the structures they are or were confronted with. What is more, considering the impact of dominant agents, so to speak, proves particularly relevant for a small and rather new academic field such as communication studies, which remained underdeveloped and without major prestige during most of its existence and, in many parts of the world, for a long time was mainly a product of external influences.

That said, many historians of communication studies would agree that beyond anniversaries and the need for legitimization by tradition, the founders and early figures of the discipline, especially in
${ }^{2}$ Jefferson Pooley, "The Declining Significance of Disciplinary Memory: The Case of Communication Research," in Handbuch kommunikationswissenschaftliche Erinnerungsforschung, ed. Christian Pentzold and Christine Lohmeier (Berlin: de Gruyter, in press).

\footnotetext{
3 Jefferson Pooley and David W. Park, Introduction to The History of Media and Communication Research: Contested Memories, ed. David W. Park and Jefferson Pooley (New York: Peter Lang, 2008), 4 .

${ }^{4}$ Maria Löblich and Andreas M. Scheu, "Writing the History of Communication Studies: A Sociology of Science Approach," Communication Theory 21, no. 1 (2011): 4

${ }^{5}$ Hans Mathias Kepplinger, "Political Correctness and Academic Principles: A Reply to Simpson," Journal of Communication 47, no. 4 (1997): 102-7. ${ }^{6}$ Pierre Bourdieu, Science of Science and Reflexivity (Chicago: Chicago University Press, 2004).
} 
the German context, have fallen into oblivion. Karl Bücher, for example, who launched the country's first communication department at Leipzig University in 1916,7 or Walter Hagemann, at the top of the West German field after World War II, ${ }^{8}$ are no longer cited, and today's students rarely know the circumstances these distant ancestors dealt with. Of course, beginning in the mid-1950s, the shift to an empirical social scientific discipline changed terminology, theories, research objects, and methods. ${ }^{9}$ For empirically oriented communication scholars in Germany, the United States became the most important point of reference. Furthermore, the distance to once leading protagonists of the field was amplified by the tendency of minimizing subjectivity and personal traces in research output and theoretical approaches. Consequently, students also learn little about the authors of even current texts.

If one argues with Jan Assmann's concept of memory, this seems unsurprising, because only a small part of the communicative memory (the recent past shared by contemporaries) passes over into the cultural memory (the absolute past fixed in storage media such as texts, icons, rituals, and performances). Once there, most of it remains in the "archive" (the canon that is available but not really present), whereas just a few references to the past are strategically used and serve as frames of orientation and identification. ${ }^{10}$ Such processes clearly also take place in academic fields, especially if they exhibit a high degree of heterogeneity and interdisciplinarity, which is, in a global perspective, still the case for communication studies. Within this framework, we see BLexKom as a research tool against oblivion that moves beyond enriching the archive. Since the biographical entries and the interview material, in particular, facilitate links between field agents, intellectual orientations, institutional traditions, and research communities that sometimes extend beyond specific content or citation, they might have an effect on the discipline's cultural memory as a whole-and even stimulate the communicative memory once again.

\section{Decision-Making as Source Providers}

The biographical entries with information about German communication scholars' origin, socialization, career steps, and key publications - at an average length of about 8 oo words-form the heart of BLexKom. Our long-term aspiration is to eventually include all scholars who teach or taught as full professors at university departments listed by the German Communication Association (Deutsche Gesellschaft für Publizistik- und Kommunikationswissenschaft) and the corresponding associations in Austria and Switzerland. Using these classifications to sketch the discipline's core is, of course, anything but unproblematic. We therefore added two more

\author{
${ }^{7}$ Hanno Hardt, Social Theories of the \\ Press: Constituents of Communication \\ Research, 1840 s to 1920 (Lanham, \\ MD: Rowman \& Littlefield, 2001), \\ 99-131; Thomas Wiedemann, Michael \\ Meyen, and Iván Lacasa-Mas, "One \\ Hundred Years Communication Study \\ in Europe: Karl Bücher's Impact on the \\ Discipline's Reflexive Project," Studies in \\ Communication and Media 7, no. 1 (2018): \\ 13-16. \\ ${ }^{8}$ Thomas Wiedemann, "Practical Ori- \\ entation as a Survival Strategy: The \\ Development of Publizistikwissenschaft \\ by Walter Hagemann," in The Interna- \\ tional History of Communication Study, \\ ed. Peter Simonson and David W. Park \\ (New York: Routledge, 2016), 116-21. \\ ${ }^{9}$ Maria Löblich, “German Publizis- \\ tikwissenschaft and Its Shift from \\ a Humanistic to an Empirical So- \\ cial Scientific Discipline: Elisabeth \\ Noelle-Neumann, Emil Dovifat and the \\ Publizistik Debate," European Journal of \\ Communication 22, no. 1 (2007): 81-84. \\ ${ }^{10}$ Jan Assmann, "Communicative \\ and Cultural Memory," in Cultural \\ Memory Studies: An International and \\ Interdisciplinary Handbook, ed. Astrid \\ Erll and Ansgar Nünning (Berlin: de \\ Gruyter, 2008), 109-18.
}


selection criteria: communication scholars who, first, hold or held a habilitation in the field, or, second, made an important contribution to the discipline such as an outstanding literature reference, which brings us to around 300 targeted encyclopedia entries. Targeting the main protagonists of the discipline with such a sample undeniably runs the risk of marginalizing those figures who focused on teaching, did not complete their habilitations, or failed to secure professorships. Yet, without any judgement, we assume that managing to give the discipline a face requires resources, and that means a permanent employment contract with a university and a minimum of purely academic reputation (i.e., for the German case, qualification degrees and publications).

In comparison, the selection criteria for our interview section are less rigid: We regularly ask renowned representatives of the field for an interview-very often on the occasion of their retirement, which allows a less inhibited look back. According to BLexKom's theoretical background (in particular, Pierre Bourdieu's sociology), these interviews of about 6,000 words systematically explore habitus patterns and capital resources and, furthermore, provide insights into the logic of the field. Nevertheless, we must take them for what they are: subjective reports shaped by personal interests that form part of each interviewee's "story about the self," ${ }^{11}$ which underlines the source character of BLexKom. Consequently, working with such research material requires a high degree of critical interpretation.

Even though we have established an editorial board and rely on the publisher's help in case of technical difficulties, we perform our duties as editors of BLexKom on a large scale. More specifically, we see ourselves as responsible for producing or soliciting new content, acquiring portrait photos and additional image material, doing the editorial work, and ensuring the timely publication of articles and updates, as well as quality management and website maintenance. Moreover, the advantages of an online platform give us the opportunity to think about innovations from time to time. When we launched our encyclopedia project eight years ago, for example, we hadn't even thought of sections like features or obituaries, which now attract a considerable number of clicks.

Our editorial activities of course also confront challenges that sometimes make a pragmatic approach necessary. In particular, given the unfinished nature of BLexKom, we have felt obliged to continuously increase the number of biographical entries and fill at least the most significant lacunae of the encyclopedia, especially at the beginning. As a consequence, despite the spirit of teamwork in our project and the fact that BlexKom counts almost seventy authors to date, we have written quite a few contributions ourselves. Writing an encyclo-
${ }^{11}$ Anthony Giddens, Modernity and Self-Identity: Self and Society in the Late Modern Age (Stanford, CA: Stanford University Press, 1991), 54 
pedia entry requires more than superficial knowledge of the history and structures of the field, as well as the right mixture of proximity and distance toward the communication scholar in question. Put differently, just another promotion tool with biographical information and mission statements is not compatible with BLexKom's vision, which is why we have decided not to have the encyclopedia entries authorized (unlike the interviews).

\section{Reactions from the Field and Lessons Learned}

Our encyclopedia project has received both encouraging feedback and criticism. The latter, which is probably more interesting here, referred, first, to BLexKom's agent-oriented approach, which (according to the critique) could crowd out the knowledge gained through intellectual and institutional histories. In addition, some commentators regarded the encyclopedia entries' personal information as too private, even irrelevant. Linked to this, some readers raised the concern that our interviews positioned interviewees in a particular way and that their statements were highly subjective, sometimes even false.

A second set of criticisms referred to the distorting effect that resulted from our project's work-in-progress character, especially in the early years, with many blind spots and, unfortunately, a considerable gender bias in the number of entries. Furthermore, some critics viewed the platform as too closely related to our own academic environment.

In a third pattern, critics lingered on the supposed power of BLexKom when writing communication study's history, and thus on the monopoly position of our project. In short, they asked: Who defines what may belong to the field's memory, and does BLexKom not first need to be officially legitimized by the German Communication Association, with all possible implications?

Similar concerns will likely confront many research projects that strive for a look behind the scenes of a discipline's development, especially when they do not always follow established paths and frameworks, or even scratch the illusio of the field. ${ }^{12}$ And indeed, there is no denying that BLexKom, with a sociological and historical sense of the field, offers some ammunition. Regarding our project, we met the criticisms received by committing to even greater transparency, openness, and self-reflection, which included initiating a two-day workshop in 2016 that allowed for an detailed discussion of the points of critique.

Beyond that, as a response to these criticisms (at the workshop and otherwise), we endeavored to provide further information about
${ }^{12}$ Bourdieu, Science of Science and Reflexivity. 
the sociology of science approach central to our biographical encyclopedia project, and to make clear that the collected interviews are also in line with our theoretical background and thus have a strictly scientific character. We further illustrated, by integrating additional sections into our platform (open as well to historiographical texts dealing with ideas and theories or with organizations and institutional settings), that BLexKom's focus on agents by no means intended to ignore the importance of other perspectives on the discipline's history and structures. Perhaps these complementary research pieces written by several historians of the field might also serve to re-emphasize the source character of BLexKom's encyclopedia entries and interviews.

Another response to the criticisms was, as mentioned, that we worked even harder to quickly eliminate as many obvious encyclopedia gaps as possible and to ensure a well-balanced and diverse spectrum of portraits, which certainly became easier as the number of biographical entries grew over the years. Related to this, we strove to increase the number of authors on our platform, especially with scholars further away from us and outside our close network (including, of course, colleagues from Austria and Switzerland).

To counter the power/monopoly position of BLexKom, we further decided to share responsibilities and to establish an editorial board consisting of four experts on the history of the German-speaking communications field, which gives our project a broader footing. In addition, we repeatedly presented BLexKom to the scientific community, explaining our approach, disclosing our decisions as editors, and providing deeper insights into the creation of content. We particularly stressed the team spirit behind our project and called for collaboration - if not with original contributions, then at least with comments and feedback, corrections and additional hints, but also with suggestions for further entries and other relevant research material.

Today, BLexKom remains an independent platform based exclusively on academic expertise that sometimes even involves students' research projects. According to its objective, we hope that BLexKom will foster research and become recognized for what it intends to be: an inspiring, at times critical, but in any case essential service to the community of German communication studies.

\section{Bibliography}

Assmann, Jan. "Communicative and Cultural Memory." In Cultural Memory Studies: An International and Interdisciplinary Handbook, edited by Astrid Erll and Ansgar Nünning, 109-18. Berlin: de 
Gruyter, 2008.

Bourdieu, Pierre. Science of Science and Reflexivity. Chicago: Chicago University Press, 2004.

Giddens, Anthony. Modernity and Self-Identity: Self and Society in the Late Modern Age. Stanford, CA: Stanford University Press, 1991.

Hardt, Hanno. Social Theories of the Press: Constituents of Communication Research, 1840 s to 1920s. Lanham, MD: Rowman \& Littlefield, 2001.

Kepplinger, Hans Mathias. "Political Correctness and Academic Principles: A Reply to Simpson." Journal of Communication 47, no. 4 (1997): 102-7. https://doi.org/10.1111/j . 1460-2466. 1997. tb02728.x.

Löblich, Maria. "German Publizistikwissenschaft and Its Shift from a Humanistic to an Empirical Social Scientific Discipline: Elisabeth Noelle-Neumann, Emil Dovifat and the Publizistik Debate." European Journal of Communication 22, no. 1 (2007): 69-88. https: //doi.org/10.1177\%2F0267323107073748.

Löblich, Maria, and Andreas M. Scheu. "Writing the History of Communication Studies: A Sociology of Science Approach." Communication Theory 21, no. 1 (2011): 1-22. https://doi.org/10.1111/ j . 1468-2885. 2010.01373.x.

Pooley, Jefferson. "The Declining Significance of Disciplinary Memory: The Case of Communication Research." In Handbuch kommunikationswissenschaftliche Erinnerungsforschung, edited by Christian Pentzold and Christine Lohmeier. Berlin: de Gruyter, in press.

Pooley, Jefferson, and David W. Park. Introduction to The History of Media and Communication Research: Contested Memories, edited by David W. Park and Jefferson Pooley, 1-15. New York: Peter Lang, 2008.

Wiedemann, Thomas. "Practical Orientation as a Survival Strategy: The Development of Publizistikwissenschaft by Walter Hagemann." In The International History of Communication Study, edited by Peter Simonson and David W. Park, 109-29. New York: Routledge, 2016.

Wiedemann, Thomas, Michael Meyen, and Iván Lacasa-Mas. “One Hundred Years Communication Study in Europe: Karl Bücher's Impact on the Discipline's Reflexive Project." Studies in Communication and Media 7, no. I (2018): 7-30. https://doi.org/10.5771/21924007-2018-1-6. 